\title{
Memory of Berlin:
}

\section{An Accidental Autoethnography}

\begin{abstract}
Although the term autobiography features regularly in the essay film literature, autoethnography appears less so. John Burgan made Memory of Berlin (1998) in his thirties, to tell the story of how he was "triggered" by the fall of the Wall in 1989 to search for his birth mother, and through this film fuses the personal with the political and historical, and explores loss, trauma and melancholy. Using the lens of autoethnography, a form of inquiry which "puts questions and 'issues of being' into circulation and dialogue" (Bochner 53), I argue that Memory of Berlin embodies this autoethnographic spirit, if not avant la lettre, then certainly without its maker's conscious engagement with theory. What is at stake in this is not merely whether or not Memory of Berlin can be described as autoethnographic in addition to autobiographical, but how identifying and understanding the autoethnographic mode might help us exemplify Catherine Russell's argument that "autobiography becomes ethnographic at the point where the film or video maker understands his or her personal history to be implicated in larger social formations and historical processes" (276). Autoethnography, then, may be a term that we can make better use of in discussions of particular instances of the essay film, regardless of whether or not a filmmaker embarks on a fully consciously methodological endeavour.
\end{abstract}

Keywords: John Burgan, Memory of Berlin, autoethnography, essay film, research, autobiography.

Mark READMAN

Bournemouth University, UK

mreadman@bournemouth.ac.uk

EKPHRASIS, 2/2021

THE ESSAY FILM

As Self-Representational Mode pp. $43-55$

DOI: $10.24193 /$ ekphrasis. 26.4

Published First Online: December 15, 2021

\section{Introduction}

John Burgan's 1998 film Memory of Berlin is an exploration of identity. It is a cinematic essay which links fragments of memory with moments in the present, generating from this synthesis forays into the nature of being. Identity in Burgan's film is fragile, relational and mutable, and the film explores the ways in which place and identity are 
interwoven. "Who would I be if...?" asks Burgan in voice-over as he speculates on different histories in different places. The Berlin Wall is presented as a metaphor for the divided self; the memorial landscape of Berlin with its scars and ruptures is not merely a potent structural device, but a psychic embodiment of the filmmaker. The film begins without preamble and we are, without warning, thrown into news footage of the fall of the Berlin Wall. After a few seconds Burgan in voice-over tells us:

November 1989. I was in London, watching the fall of the Berlin Wall on television. This city coming together seemed to open up a fault in me. Then, a memory. Berlin. Summer 1967. Home movie images I had often seen as a child. But something was missing. Something was missing in me. I had no words to describe this feeling, I just knew I had to go back. Back to the beginning. Back to where it all started.

The spine of the film is the quest — first for his mother, and then his father — which necessitates an actual journey, but the journey is also an introspective one, characterised by meditations prompted by fragments from the past, such as home movies, photographs, news archive, maps, letters and childhood objects. And the literal journey produces its own artefacts - records of travelling and objects rendered potent by association, for example, with meta-discursive elements in which the apparatus of production is foregrounded. The film is 'about' much more than the question 'who am I?', being bookended by reflections on the impact of adoption on one's sense of self. The ghost is a central figure in the film, its significance indicated when Burgan tells us, in voice-over:

Being adopted is like being your own ghost, a ghost who's the same age, the same height, has the same features, the same likes, the same dislikes, even the same obsessions. Identical in every detail, except he has another name; that of the person I could have become.

\section{The Autoethnographic Lens}

Although the term autobiography features regularly in the essay film literature, autoethnography rarely does. There is no mention of it at all in key texts by, for example Alter (The Essay film After Fact and Fiction), Alter and Corrigan (Essays on the Essay Film), Corrigan (The Essay Film: From Montaigne After Marker), Rascaroli (How the Essay Film Thinks), and only one mention in passing by Elsaesser and Piotrowska ("Lovers in Time”). Catherine Russell's concluding chapter of Experimental Ethnography, however, focuses explicitly on autoethnography, drawing on writing by Michael Fischer and Mary Louise Pratt, who see autoethnography as a critical response to the colonialism and othering 
inherent in ethnography. Nevertheless, Russell does not draw on more recent work from the social sciences, which identifies specific characteristics of autoethnographic work and marks it out as both an ethical and creative project. By enhancing her discussion with such literature, and illuminating it in relation to Memory of Berlin, one can better understand what this mode looks like in the essay film.

The essay film is overtly a "critical mode of enquiry" (Hollweg and Krstić 1) and, therefore, often aligns with academic research, without necessarily being conceived as such. Timothy Corrigan, in tracing the origins of the essay film, and Kitrina Douglas and David Carless, in tracing the origins of autoethnography, all gravitate towards Michel de Montaigne who "was offering meditations based on personal reflection as long ago as 1500 " (Douglas and Carless 89) which "testify not only to the constant changes and adjustments of a mind as it defers to experience but also to the transformation of the essayistic self as part of that process" (Corrigan 13). Of course, not all essay films are autoethnographic or even autobiographical, but when the filmmaker becomes the object as well as the subject of the interrogative process, and uses this mode to explore trauma and vulnerability, we are in autoethnographic territory.

This is an attempt, then, to produce insights into one particular instance of the essay film by subjecting it to autoethnographic questioning and, in doing so to identify precisely how some of those familiar features, such as "subjectivity, reflexivity, hybridism, dialogism, voiceover commentary [...] and autobiographical elements" (Rascaroli 15), are mobilised in the service of a project which combines the personal and the political. Autoethnography, as Arthur Bochner (53) points out, was a term introduced into the social sciences by David Hayano who in turn recalls hearing the term in one of Sir Raymond Firth lectures in the 1960s. Both Firth and Hayano were anthropologists and Hayano's use of the term, as a kind of self-aware ethnography by those who either are, or have gone, 'native', is different from the way in which autoethnography flourished as an approach in the 1990s as a form of deep, personal narrative enquiry (again, see Bochner, as well as Holman Jones et al.) I make this point because the making of Memory of Berlin was contemporaneous with this flourishing, although Burgan, by his own admission, was unaware of the autoethnographic 'revolution' in the social sciences (Burgan, interview). Without a direct causal relationship between this theory and the director's practice, there is nevertheless a remarkable congruence between the two, as will become apparent.

The essay film and autoethnography often dwell on issues of time and memory, and it is also notable that both Memory of Berlin and autoethnography begin with a sense of 'something missing'. In his film Burgan observes that "something was missing. Something was missing in me. I had no words to describe this feeling [...]”. Similarly, Douglas and Carless talk about their autoethnographic "epiphanies" which relate to "an initially ill-defined sense or awareness that something was missing from the academic writings and communications 
we were studying and accessing” (85). Although Burgan's sense of absence is ontological and Douglas and Carless's is epistemological, both achieve a kind of authenticity and 'wholeness' via journeys of discovery. This is more than a felicitous coincidence, then.

This discussion draws upon some of the key criteria for conceptualising autoethnography proposed by Stacy Holman Jones, Tony Adams and Carolyn Ellis, who argue that "while all personal writing could be considered examinations of culture, not all personal writing is autoethnographic" (22), and we might extend the notion of "writing" to include filmmaking. The "additional characteristics" which make the distinction are: an engagement with culture and cultural practices; a sense of contributing to existing research; creating a reciprocal relationship with audiences; and, crucially, embracing vulnerability with a purpose (Holman Jones et al. 22). These qualities from the discourse of social science chime with Michael Renov's notion of the 'new autobiography' in documentary which, he argues, is characterised by "a forceful reflex of self-interrogation" and an "obsessive exploration of subjectivity" (105).

I argue that Memory of Berlin embodies this autoethnographic spirit, if not avant la lettre, then certainly without its maker's conscious engagement with theory. What is at stake in this is not merely whether or not Memory of Berlin can be described as autoethnographic as well as autobiographical, but how identifying and understanding the autoethnographic mode might help us exemplify Catherine Russell's argument that "autobiography becomes ethnographic at the point where the film or video maker understands his or her personal history to be implicated in larger social formations and historical processes" (276). Autoethnography, then, may be a term that we can make better use of in discussions of particular instances of the essay film, regardless of whether or not a filmmaker embarks on a fully consciously methodological endeavour.

\section{"New Autobiography" and the Autoethnographic Imagination}

When Michael Renov, in 2004, talks about the "new autobiography" he attempts to describe the essay film with an autoethnographic quality. He argues:

In singling out this version of the essay from all the others [...] I privilege a writing practice that couples a documentary impulse-an outward gaze upon the worldwith an equally forceful reflex of self-interrogation. This double or reciprocal focus effects an unceasing, even obsessive, exploration of subjectivity that situates itself within a matrix that is irreducibly material and of necessity historical. Crucial to an understanding of such a writing practice is thus its construction of a subjectivity at odds with the dichotomous subject object model of Descartes. (105) 
Miriam De Rosa, responding to Renov's prompt, writes that "the concept of autoethnography is a representational form tightly linked to that of autobiography" and that "the author $[. .$.$] has to be the one carrying out the action of telling the story, that ends up$ being his own" (530-31). The difference is one of depth; autobiography indicates a self, a life and a form of inscription, whereas autoethnography signifies a self, a culture and a form of inscription. In the latter "authors use their own experiences in a culture reflexively to look more deeply at self-other interactions within structures and institutions of power and knowledge" (Dutta and Basu, 149).

It is these qualities which characterise Memory of Berlin - the "unceasing, even obsessive, exploration of subjectivity" and its strategy of making the subject into the object of the film. It tells an intensely personal story, but it also speaks to broader cultural concerns, from the “ontological insecurity" explored by R. D. Laing in The Divided Self to Jacques Lacan's notion of the ruptures brought about by the individual's entry into the symbolic realm and "the individual's desire to be the possessor and the resident of a secure bodily ' $\mathrm{I}$ '” (Bowie 26). It also explores the relationship between identity and geopolitics - explicitly so in the first few minutes of the film which make the link between the nascent reunification of Germany and the 'fault' which it opens in the filmmaker. This 'fault' is then explained in the film through the use of archive images and autobiographical detail about Burgan's origins:

It's February 1962, the first picture of myself and my mother in London. I am called Matthew. It will be 33 years before I see the photo and learn my original name. Being adopted was so normal I never thought about searching for my birth mother. I knew a little about my origins. She came from an Irish family and worked for a national newspaper. My father was Australian. They met in summer 1961, had a love affair, and nine months later there I was. Six weeks after the photo was taken my mother travelled alone to the North to a Catholic adoption home in Middlesbrough. She believed she would never see the baby again. Five days later: my new mum, Kathleen, is holding me in a back yard in Hull. Behind the camera is my dad, Arthur. Now I am called John. The first photo of us together-a new family, a new name, a new home. Mum always says "John, I love you as you are", but who is it that she loves? Two photos, two mothers, two fathers and two of me. Whatever happened to that other baby, Matthew? Did he stop existing in April of that year, or is he somewhere in the world, wandering like a ghost?

(voice-over)

There are some elements in this sequence which go beyond autobiography: the use of tenses, for example. Historical detail about Burgan's birth parents uses the simple past ("she worked", "they met"), but when the subject is himself Burgan uses the historical present tense ("I am called Matthew", "my new mum [...] is holding me"). This device signifies 
a high degree of reflexivity about identity -identity here is not fixed, is not linear, is not chronological, but rather it is in a perpetual state of flux and is constituted by the past being active (not merely recollected) in the present. There is also a visual device employed in this sequence; the rostrum shots of the photographs of mothers and babies are interrupted by archive footage of the erection of barriers across Berlin — the words "nine months later" coincide with barbed wire being rolled out to carve the city in two. This is not merely historical 'colour' (in fact the wall's construction commenced a year earlier in 1961), but rather the inscription of a symbolic scheme in which geopolitical divisions are analogous with psychic divisions. The film both reflects on political and geographical ruptures and also speaks to the psychic makeup of the individual — desiring wholeness and haunted by disintegration. There is a striking sequence later in the film (an homage to Elem Klimov's Come and See / Idi I Smotri, as Burgan admits in an email) later in the film where time is reversed, trains go backwards, collapsed buildings are reconstructed, the Berlin Wall is closed again. There is a sense of wounds being 'healed' — "demolishing to rebuild" as the narrator of the German archive footage says in the film.

Carolyn Ellis argues that "autoethnography requires that we observe ourselves observing, that we interrogate what we think and believe, and that we challenge our own assumptions, asking over and over if we have penetrated as many layers of our own defences, fears, and insecurities as our project requires" (10). Less than a minute into the film there is a big close up of Burgan's eye - the filmmaker turns the lens on himself — which seems to literalise this notion of observing oneself observing, with a nod to the reflexivity of Dziga Vertov's Man with a Movie Camera / Celovek s kinoapparatom. There are also multiple references in the film to watching, seeing and observing, along with doubles, mirrors and reflections. This aesthetic scheme, again, shifts the register of the film so that it is more than merely autobiographical, but rather it uses the medium of representation to interrogate the very status of self and identity.

The self, personal history, and memory in this film are imbricated with news footage, politics and geography. Burgan refers to an email from US filmmaker Robert Kramer who, in response to seeing his work in progress in 1997 wrote:

the real heart of the essay [film] is...oneself. And the real challenge is to find the right way to release that self in terms of the unfolding images. In fact, "self" is a fiction to be manipulated, to be written, with the same requirements it would have if it was only another role, another character that you were trying to develop. (Burgan, email)

This conception of the self, a non-essential conception, is always in tension in a film with a strong sense of authorship. Authorship implies a unitary self - there is an "I" in the film, a point of enunciation, but the film undermines this stability through its uncertainty about 
the nature of the self. The "who am I?" question which underpins much autoethnographic work is reinforced here because the conditions of Burgan's origins render the usual certainties of name and heritage insecure. Memory, therefore, is based on technologies of reproduction - the $8 \mathrm{~mm}$ home movies of his childhood that his adoptive parents shoot and screen become his memories and the technology of recording is instrumental in this, such as "the sound of that camera recording our future memories", the voice-over tells us. Similarly, his father's commentary on these movies when they are regularly screened to the assembled family is framed technologically: "I can remember that voice-over as if it is a loop which has been running in my mind ever since. How does the commentary go? [...] John's a good boy - quiet and well-behaved. He's from good stock — he's got breeding” (voice-over). This "loop" (a magnetic tape metaphor) has persisted from childhood to adulthood-a memory of a commentary on a memory - and, tellingly, repeats an assertion about origins and heritage ("breeding") which cannot be proved and, therefore, reinforces an absence that must be filled.

Autoethnography in the social sciences has been championed by those in marginalised settings and framed ideologically as a postcolonial project. The imperialist tradition of ethnography is challenged by focusing on, as Dutta and Basu put it, the "embodiment of the researcher's emotional and bodily ways of knowing and experiences of difference [...] and how these experiences influence implications for knowledge generation" (149). Russell, similarly, notes that Pratt's "attribution of this genre to marginalized subjects is characteristic of writing on autoethnography” (277). Burgan's identity in Memory of Berlin is marginal, although not in terms of gender, sexuality of even class, but fundamentally in terms of his sense of belonging, hence the visual emphasis on guarantors of existence - photographs, home movies, his birth certificate, for example. Near the beginning of the film there is a sequence of shots on the beach near Hull where he grew up: first he is alone, gazing at the camera, then we see his adoptive parents, and then he is pictured with his adoptive mother. He speculates, in voice-over, about the difference between nature and nurture, and what he might have acquired from his parents. The poses, reminiscent of family snapshots, are held for just too long, the gaze at the camera becomes uncomfortable, the seasonal chill is evident in their clothing and the sense of being pinched by the cold. This tension speaks to marginality - the overt function of the images is to signify belonging and family connection, but the strain shows and it is awkward. The montage and shot duration indicate an underlying instability, whilst attempting to assert stability. It is reminiscent of how Stacy Holman Jones conceives her approach to research in which adoption is 'storied' and understood. She asks, at the end of a richly theorised set of narratives and experiences:

What have I produced in my telling of/in/on adoption stories? First, that adoption stories are spaces and stages for negotiating the performance/performativity dynamic [...] adoption stories are telling discussions of how known origins, given identities, and stable homes come to constitute the very ground from which we 
created notions of self, family, culture and critique. They are particular performances that, in their self-conscious construction, raise questions about the relationship among bodies and identities, rights and responsibilities, institutions and effects. (“(M)othering Loss" 126)

The performance of identity and its creative treatment in Memory of Berlin do not merely relay the facts of a life, but they unpack assumptions and certainties in order to subject them to scrutiny.

The autoethnographic process has much in common with therapy, albeit a therapeutic encounter in which the researcher/filmmaker is both analyst and analysand, with all of the problems that might accompany their duality. In both scenarios issues of (childhood) trauma and their resonance in adulthood are addressed, and in both we find attempts to rationalise, to deny, to condense and to displace.

\section{Autoethnography as Therapeutic Encounter}

Memory of Berlin is in many ways a highly controlled film - the emotions of the filmmaker are often devolved onto figures from the past — the freeze frame of the weeping East German man passing through the wall for the first time, for example-and the voiceover is characterised by gravitas, providing weight, but not emotion to statements such as:

I didn't know it at the time but the fall of the wall was the start of the long search for my birth mother. It would be another three years before I took the first steps on a very lonely journey. I had to leave home, distance myself from the familiar. There was only one place I could go-the city I had once visited by chance as a child, but whose images had become part of my life. (Voice-over)

There are a number of things at work which illuminate the nature of autoethnography in this film. It is designed as a quest story and through this, and other familiar tropes, it attempts to contain emotion. Burgan admits as much, when he explains why he chose not to make a video diary:

The video diary was an obvious model that the project could have adopted, in fact a path recommended by some friends and advisors; but I quickly realised that sharing my feelings in real time in front of the camera, even if alone, was simply not going to work. Telling the story in reflection, using the essay mode, composing and revising the commentary offered me a much greater degree of control. (Burgan, interview) 
The aesthetic scheme of the film, then, becomes increasingly recognisable as a protective carapace - a way of processing trauma without having to confront it directly. In this sense we might draw on Freud's work on dreams to understand ways in which stories and imagery represent condensed and/or displaced representations of unconscious desires and anxieties — "the manifest dream-content deals with quite different material from the latent thoughts" (Freud 99). This Freudian framework enables us to see how Memory of Berlin is caught between a rational, sober description of a journey into the past, and a series of dreamlike displacements which erupt into the impassive narration. The narration might even effect misdirection in places when it uses the language of psychoanalysis, referring to fantasies, psychic intuition, nightmares and hallucinations. The implication is that the narrator, knowing this language and understanding these structures, has already done the work of analysis and cannot be caught out by it. But, nevertheless, there are moments when the film seems to betray its narrator by breaking through this cool control. The 'Russian dog' sequence, which occurs almost exactly at the mid-point in the film, is one such rupture.

Given Burgan's disavowal of the video diary, it is interesting that the 'dog sequence' appearing in a larger segment set in Smolensk, was shot on Video8. There is one shot of Burgan in a mirror, in this sequence from 1991, in the USSR, when he tells us (with apparent satisfaction) that he has captured images (unlike in Berlin) just before the fall of communism. The implication is that he 'made it' before the USSR disintegrated, thus deriving some solace from wholeness. But in this scene there is a sense of the filmmaker, whilst trying to assert control over his material (using the medium to freeze time before nations and people are torn apart), also losing that control. In one of the most striking sequences in the film, as one of his Russian hosts sings a traditional song about being far from home and away from one's mother, we have the long shot (in every sense - long lens and long duration) of a bedraggled dog trotting along in the snow, alone. Whenever someone walks by it follows them hopefully for a while before giving up and following someone else. The sequence finishes on a freeze frame and fade to black with the dog alone again. It is easy to read this symbolically, either on a personal or an existential level, but, as with the portraits on the beach it is the duration of the sequence which represents the rupture. The scene takes place in someone's home - a convivial gathering in Smolensk. The song is a melancholy one and while it plays Burgan shoots the street scene from the window in grainy Video8. It is snowy, the pavements flanked by filthy slush, his eye is caught by the pitiful dog and the camera dwells on it and follows it for more than two minutes. It is as if at this moment of attempting to capture the comforts of a state of pre-dissolution, the attempt is undermined by what the Welsh call hiraeth and the Germans call Sehnsucht-a longing, a yearning for that which is out of reach and cannot be articulated in his own language, embodied in this small, sad dog. Burgan speaks about this scene in a way which 
sidesteps the theoretical and which emphasises the intuition of the artist:

Even though it was entirely unanticipated, captured by happenstance at the end of a long lens, it's a scene I recognised as soon as I saw it happening [...] I didn't know how I was going to use the dog-perhaps it's the way a photographer might work. I recall Diane Arbus saying something similar, about being not sure what she is looking for but she knows it when she sees it: "it's what I've never seen before that I recognise" [(Tatham 567)]. A photographer might be in completely unfamiliar territory but if they have thematic consistency in their work-they know instinctively when something will be useful. The dog was like that: I had no idea how I was going to use it, and in the end, it found its place as the result of a long process of editing. But when I saw the dog I didn't have to wonder whether to film it. (Burgan, interview)

This emphasis on intuition, on the highly attuned senses of the artist (the comparison with Arbus is significant) masks the function of the dog as an embodiment of pain and loss; "autoethnographic writing" as Anderson and Glass-Coffin argue, "is most successful when it is evocative, emotionally compelling, and when readers can feel their lives deeply touched by the stories that they read" (75). The dog, using Freud's psychoanalytical framework, is by virtue of its duration, a form of displacement - a shorter sequence would have made it easier to read as metaphorical, but there is something (to use Renov's words again) "unceasing, even obsessive" about this sequence which makes it less easy to analyse, less easy to pin down and, therefore, more profound.

There is much in this film which fits Russell's description of "new autobiography":

Family histories and political histories unfold as difficult processes of remembering and struggle. Specific, resonant images echo across distances of time and space. Documentary truth is freely mixed with storytelling and performances. (278)

There are also elements which resist aesthetic control and organisation, which despite having a rational 'anchor' in the film are also overdetermined; there is an excess which reaches for something inchoate beyond the rational scheme. Burgan has cast himself as the central character in this drama, but the danger with becoming object as well as subject is that one may be caught out by what one feels. A comparable sequence at the Berlin Zoo, for example, seems only to be governed by the logic of illustration; the voice-over which follows it tells us:

The city's split. There's two of everything: two observatories, two state libraries, even two zoos. But if I ever get lost in Berlin, there it is [shot of the Fernsehturm] [...] it conceals a wound at the heart of Berlin. The big, somewhat bloodshot unblinking eye looking out over the city. I see it. It sees me. Watches me. Wherever I am. 
But during the sequence the camera dwells on a child watching a keeper wash the windows in the primate enclosure, following the keeper's movements, rapt. Later a juvenile gorilla dressed in a baby's 'onesie' paws at the tiled walls before appearing to surrender to the conditions of captivity.

At such times, when the voice-over is silent, there is a sense of authorial abnegation, as if the narrator forgets it is a film and allows it to simply run, perhaps looking for clues of presence or absence, drawn to abjection because such images demand attention. The analyst might suggest that the analysand is prepared to speak rationally about feeling divided and adrift, but that the displacement onto images of abjection removes the need to say "I am hurt".

\section{Conclusions}

My argument in this article has been driven by the idea that autoethnography is a term that is more valuable and useful than has been recognised in the field of the essay film-it helps us to make nuanced distinctions between that which is 'merely' autobiographical and that which plunges into uncertainty about the culturally embedded nature of self, identity and truth. Both Renov and Russell have attempted to move the notion of autoethnography into a more visible position in discussions of the essay film, Renov from the perspective of the "new autobiography" and Russell from the perspective of experimental ethnography. Although Burgan cites Chris Marker's San Soleil as a key influence (Burgan, interview), Marker "hides himself within an intricate pattern of first-person pronouns" (Russell, 301) in order to decentre himself. Burgan, conversely, is explicitly centred in his film although, as I have suggested, there are mechanisms at work in the film which find analogues in psychoanalytic encounters.

Burgan's adoption story lends itself perfectly to a film treatment which problematises the nature of subjectivity, the relationship between truth and fantasy and the divided self. Catherine Russell could be describing his film when she attempts to conceptualise the 'ethnographic autobiography':

An ethnographic subjectivity, a self that understands itself as culturally constituted, is fundamentally split in the autobiographical mode. Even when the subject in history is constructed as a point of origin for memories, geographic and spatial distance comes to evoke a distance in time that separates different moments of the self. (280)

The strategy of the film, to place identity under scrutiny and show how it is composed of fragments of the past, chimes with Russell's assertion that "autoethnography produces a subjective space that combines anthropologist and informant, subject and object of the 
gaze, under the sign of one identity" (312). In her discussion of Jonas Mekas's diary films (credited as "prototypical autoethnographies") she notes how "Mekas inscribes himself as a journey, as a survivor of his own past" (283) and how the poetic construction of the films is designed to "salvage an identity" (282). This sense of writing oneself into a story and using the creative means at one's disposal to make sense of trauma, chaos and loss, to achieve narrative coherence through art if not life, is a necessary condition of autoethnography, and the growing understanding of it in the social sciences can help us make sense of its manifestations in the essay film.

There is often a quality of the essayistic in autoethnography generally - a sense of thought being explored and clarified - and those essay films which deeply examine personal histories can be vivid exemplars of the autoethnographic mode. This, as is the case with Memory of Berlin, I suggest, may be despite the filmmaker's lack of conscious understanding of the methodologies of autoethnography, or intention to 'do' autoethnography.

\section{Works Cited}

Alter, Nora M. The Essay Film After Fact and Fiction. Columbia University Press, 2018.

Alter, Nora M., and Timothy Corrigan, editors. Essays on the Essay Film. Columbia University Press, 2017.

Anderson, Leon and Bonnie Glass-Coffin. "I Learn by Going: Autoethnographic Modes of Inquiry.” Handbook of Autoethnography, edited by Stacy Holman Jones, and Carolyn Adams, Routledge, 2013, pp. 57-83.

Bochner, Arthur P. "Putting Meanings into Motion: Autoethnography's Existential Calling." Handbook of Autoethnography, edited by Stacy Holman Jones, Tony E. Adams and Carolyn Adams, Routledge, 2013, pp. 50-56.

Bowie, Malcom. Lacan. Fontana Press, 1991.

Burgan, John. Personal interview. By Mark Readman, 21 May 2021.

—. "Re: Memory of Berlin article". Received by Mark Readman, 30 July 2021.

Come and See /Idi I Smotri. Directed by Elem Klimov. Mosfilm/Belarusfilm; Sovexportfilm, 1985.

Corrigan, Timothy. The Essay Film: From Montaigne, After Marker. Oxford University Press, 2011.

De Rosa, Miriam. "The Place of the Self: Auto-Ethnographic Filmic Writings and Space." Comunicazioni sociali, vol. 3, 2012, pp. 529-41.

Douglas, Kitrina, and David Carless. “A History of Autoethnographic Inquiry.” Handbook of Autoethnography, edited by Stacy Holman Jones, Tony E. Adams, and Carolyn Ellis, Routledge, 2013, pp. 84-106.

Dutta, Mohan J., and Ambar Basu. "Negotiating Our Postcolonial Selves: From the Ground to the Ivory Tower." Handbook of Autoethnography, edited, Stacy Holman Jones, Tony E. Adams and Carolyn Ellis, Routledge, 2013, pp. 143-61. 
Ellis, Carolyn. "Carrying the Torch for Autoethnography." Handbook of Autoethnography, edited by Tony E. Adams, Stacy Holman Jones Tony E. Adams and Carolyn Ellis, Routledge, 2013, pp. 9-12.

Elsaesser, Thomas, and Agnes Piotrowska. "Lovers in Time: An Essay Film of Contested Memories." World Cinema and the Essay Film: Transnational Perspectives on a Global Practice, edited by Brenda Hollweg and Igor Krstić, Edinburgh University Press, 2019, pp. 138-56.

Freud, Sigmund. The Essentials of Psychoanalysis. Translated by James Strachey, Pelican, 1986.

Hayano, David M. “Auto-Ethnography: Paradigms, Problems and Prospects." Human Organisation, vol. 38, no. 1, 1979, pp. 99-104.

Hollweg, Brenda and Igor Krstić. "Introduction." World Cinema and the Essay Film: Transnational Perspectives on a Global Practice, edited by Brenda Hollweg and Igor Krstić, Edinburgh University Press, 2019, pp. 1-18.

Holman Jones, Stacy, Tony E. Adams, and Carolyn Ellis. "Introduction: Coming to Know Autoethnography as More Than a Method." Handbook of Autoethnography, edited by Stacy Holman Jones, Tony E. Adams and Carolyn Ellis, Routledge, 2013, pp. 17-47.

Holman Jones, Stacy. “(M)othering Loss: Telling Adoption Stories, Telling Performativity.” Text and Performance Quarterly, vol. 25, no. 2, 2005, pp. 113-35.

Laing, Ronald David. The Divided Self: An Existential Study in Sanity and Madness. Penguin, 1965. Man with a Movie Camera / Celovek s kinoapparatom. Directed by Dziga Vertov, VUFKU, 1929.

Memory of Berlin. Directed by John Burgan. ÖFilm, ZDF, 1998.

Rascaroli, Laura. How the Essay Film Thinks. Oxford University Press, 2017.

Renov, Michael. The Subject of Documentary. University of Minnesota Press, 2004.

Russell, Catherine. Experimental Ethnography: The Work of Film in the Age of Video. Duke University Press, 1999.

Sans Soleil. Directed by Chris Marker. Argos Films, 1983.

Tatham, Michael. "Unaccommodated Man: The Photography of Diane Arbus." New Blackfriars, vol. 55, no. 655, 1974, pp. 563-67. 